\title{
Genetic Analysis of the Fused Vein Trait in Cucurbita pepo L.
}

\author{
R. Bruce Carle and J. Brent Loy \\ Department of Plant Biology, University of New Hampshire, Durham NH 03824
}

Additional index words. gametophytic subvital

\begin{abstract}
The expression and inheritance of the fused vein trait in Cucurbita pepo were investigated. The fused vein inbred, NH2405, was crossed to normal lines, $\mathrm{NH614}$, and $\mathrm{NHBP10}$. Reciprocal $\mathrm{F}_{1}, \mathrm{~F}_{2}, \mathrm{~F}_{3}$ and $\mathrm{BC}$ populations were generated and examined for leaf type segregation in field and greenhouse environments. Although the fused vein phenotype is stable in NH2405, it exhibited a continuum of expression in segregating populations. The onset of vein fusion ranged from the fourth to the tenth leaf stage and degree of fusion varied from slight $(1-5 \mathrm{~cm})$ to extreme $(10-20 \mathrm{~cm})$. Inheritance ratios varied with population, conditions of production, and direction of cross. Most segregating populations fit either a single or double recessive gene model, however, a quarter of the populations showed no or low fused vein recovery. A feasible explanation for the distorted inheritance is that the fused vein trait is a gametophytic subvital, governed by a single recessive gene, $f v$. Although less likely, a double recessive, subvital model cannot be ruled out.
\end{abstract}

Hull-less seeded pumpkin cultivars are particularly prone to contamination. They are morphologically similar to many hulled pumpkins and their seed stocks are maintained and produced in the same agricultural region. Hull-less seed acreage is comparatively small, and adequate isolation is difficult to obtain. The hull-less trait is determined by a maternally expressed recessive gene, $n$ (Grebenscikov, 1954; Stuart, 1983). Outcrossing by hulled genotypes can remain undetected for two generations allowing widespread contamination of stock and commercial seed lots.

A new leaf mutant, fused vein (FV), has potential as a roguing marker for pumpkins. The FV trait is expressed before flowering and imparts a distinctive, readily visible, leaf morphology (Carle and Loy, 1996a). The trait is not present among current Cucurbita pepo cultivars; limiting its use to hull-less material would provide broad outcross detection from hulled contaminants. The purpose of this study was to assess the utility of the FV trait as a production marker. Using selected breeding lines, the trait's inheritance and expressivity were determined.

\section{Materials and Methods}

Plant material. Cucurbita pepo inbred bush lines, NH2405, NH614, NHBP10, and NH7210, developed at the Univ. of New Hampshire (UNH), were used to study the inheritance of the FV trait. NH2405, a hull-less seeded $\mathrm{F}_{7}$ line, served as the FV parent in all studies. The lines NH614, a hull-less $\mathrm{F}_{6}$, and NHBP10, a homozygous hulled $\mathrm{F}_{5}$, functioned as normal $(\mathrm{N})$ leaf parents. NH7210, a hull-less $\mathrm{F}_{5}$, is distantly related to $\mathrm{NH} 2405$; its moderately fused phenotype enabled the examination of complementation, whether phenotypic variation results from intra- or intergenetic interactions.

Inheritance study I. In Spring 1990, hand-pollinated, reciprocal crosses were made between $\mathrm{NH} 2405$ and NH614 in the UNH greenhouse. The following summer, $11 \mathrm{~F}_{2}, 16 \mathrm{FV} \mathrm{BC}$ and $9 \mathrm{~N} \mathrm{BC}$ populations were generated over a 3-week period in the field at the Woodman Horticultural Farm, Durham, N.H. In Fall 1990,48 seeds each of $7 \mathrm{~F}_{2}$ populations and 30 seeds each of $17 \mathrm{BC}$ populations were sown in $15-\mathrm{cm}$ (1.9-liter) pots in the UNH greenhouse. Resulting

Received for publication 23 Jan. 1995. Accepted for publication 10 July 1995. Scientific contribution no. 1891 from the New Hampshire Agricultural Experiment Station, Durham, The cost of publishing this paper was defrayed in part by the payment of page charges. Under postal regulations, this paper therefore must be hereby marked advertisement solely to indicate this fact, plants were grown until the tenth leaf stage and scored for leaf type. In Summer 1991, 100 seeds of each $\mathrm{F}_{2}$ population, 50 seeds of each FV BC population, and 50 seeds each of four NBC populations were planted on 31 May at the Woodman Farm. Following droughty weather and poor stand establishment, the remainder of $\mathrm{F}_{2}$ and $\mathrm{BC}$ seeds were used to replant on 10 June. Resulting plants were scored for leaf type at the tenth leaf stage, at first flower, and following peak bloom. During the summer of $1991, \mathrm{~F}_{3}$ populations were generated by hand-pollination of $\mathrm{F}_{2}$ plants exhibiting various leaf phenotypes. The following fall, nine $\mathrm{F}_{3}$ populations were grown and scored in the greenhouse in the manner used previously for the greenhouse $F_{2}$ populations.

Inheritance study II. In Spring 1991,4 $\mathrm{F}_{2}$ and 6FV BC populations were generated using $\mathrm{NH} 2405$ and $(\mathrm{NH} 2405 \times \mathrm{NHBP} 10) \mathrm{F}_{1}$ in the UNH greenhouse. That same summer, 50 seeds from each population were planted and replanted in the field, and the resulting plants were scored for leaf type three times as in the previous study. $\mathrm{F}_{3}$ populations were generated during the summer by hand-pollination of selected $\mathrm{F}_{2}$ plants. Forty seeds each from $7 \mathrm{~F}_{3}$ populations were sown and the resulting plants scored at the tenth leaf stage in the greenhouse during the spring of 1992.

Inheritance study III. In Spring 1991, $\left(\mathrm{NH} 2405 \times \mathrm{NH}^{2} 210\right) \mathrm{F}_{1}$ was used to generate three $\mathrm{F}_{2}$ populations and six BC populations, three to each parent. That same summer, 25 seeds from each population were planted and replanted in the field, and the resulting plants scored for leaf type three times as in the previous studies.

Analyses. Chi-square analyses were performed for $\mathrm{F}_{2}, \mathrm{BC}$, and $\mathrm{F}_{3}$ populations, using one- and two-gene models for determining expected ratios. Field and greenhouse inheritance data were pooled for individual populations where appropriate. $\mathrm{F}_{2}$ and $\mathrm{BC}$ population sizes and genetic models were selected based on observation of initial breeding material.

\section{Results}

Recessive inheritance. Throughout primary plant growth, $\mathrm{F}_{1}$ plants $(\mathrm{NH} 2405 \times \mathrm{NH6} 14, \mathrm{NH} 614 \times \mathrm{NH} 2405$, and $\mathrm{NH} 2405 \times$ NHBP10) produced leaves of $\mathrm{N}$ phenotype. Progeny of $\mathrm{N}$ backcrosses also developed $\mathrm{N}$ leaves and confirmed the recessive nature of the FV trait. Late in the 1990 and 1991 growing seasons, however, some F, plants derived from NH2405 $\times$ NH614 and NH614 $\times$ NH2405 developed FV terminals on one or more lateral stems. In 1991, $62 \mathrm{FV}$ terminals were observed among $158 \mathrm{~F}_{1}$ plants. Rooted greenhouse cuttings of 25 altered terminals contin- 
Table 1. Fused vein segregations in $\mathrm{F}_{2}$ populations' derived from crosses between $\mathrm{NH} 2405$ (fused vein) and NH614 (normal).

\begin{tabular}{|c|c|c|c|c|c|c|c|}
\hline \multirow[b]{2}{*}{ Cross } & \multicolumn{3}{|c|}{ Phenotype $^{y}$} & \multicolumn{2}{|c|}{$3: 1$} & \multicolumn{2}{|c|}{$15: 1$} \\
\hline & $\mathrm{N}$ & FV & $S^{x}$ & $\chi 2^{w}$ & $P$ & $\chi 2^{w}$ & $P$ \\
\hline \multicolumn{8}{|c|}{$\mathrm{NH} 2405 \times$ NH614 $\mathrm{F}_{2}$} \\
\hline $90-1$ & 86 & 22 & 3 & 1.23 & $0.50-0.25$ & 36.75 & $<0.005$ \\
\hline $90-2$ & 80 & 4 & 2 & 18.35 & $<0.005$ & 0.32 & $0.75-0.50$ \\
\hline $90-3$ & 96 & 0 & 1 & 32.00 & $<0.005$ & 6.40 & $0.02-0.01$ \\
\hline $90-4$ & 87 & 7 & 2 & 15.45 & $<0.005$ & 0.23 & $0.75-0.50$ \\
\hline $90-5$ & 25 & 9 & 2 & 0.04 & $0.90-0.75$ & 23.73 & $<0.005$ \\
\hline $90-6$ & 66 & 0 & 0 & 22.00 & $<0.005$ & 4.40 & $0.05-0.02$ \\
\hline $90-7$ & 40 & 22 & 4 & 3.63 & $0.10-0.05$ & 90.43 & $<0.005$ \\
\hline $90-8$ & 53 & 20 & 4 & 0.22 & $0.75-0.50$ & 55.72 & $<0.005$ \\
\hline \multicolumn{8}{|c|}{ NH614 $\times$ NH2405 F } \\
\hline $90-1$ & 126 & 2 & 6 & 37.50 & $<0.005$ & 4.80 & $0.05-0.02$ \\
\hline $90-2$ & 136 & 0 & 0 & 45.33 & $<0.005$ & 9.07 & $<0.005$ \\
\hline $90-3$ & 120 & 0 & 1 & 40.00 & $<0.005$ & 8.00 & $<0.005$ \\
\hline Combined & 915 & 86 & 25 & 143.74 & $<0.005$ & 9.37 & $<0.005$ \\
\hline Homogeneity & & & & 72.05 & $<0.005$ & 230.48 & $<0.005$ \\
\hline
\end{tabular}

${ }^{\bar{\lambda}}$ Field and greenhouse plantings combined.

'Phenotypes: $\mathrm{N}=$ normal, $\mathrm{FV}=$ fused vein, $\mathrm{S}=$ sectored plant.

${ }^{x}$ Sectored data omitted from analyses.

" $x 2$ df: individual, 1; combined, 1; homogeneity, 10 .

Table 2. Fused vein segregations in testcross populations ${ }^{2}$ derived from crosses between NH2405 (fused vein) and NH614 (normal).

\begin{tabular}{|c|c|c|c|c|c|c|c|}
\hline \multirow[b]{2}{*}{ Cross } & \multicolumn{3}{|c|}{ Phenotype $^{y}$} & \multicolumn{2}{|c|}{$1: 1$} & \multicolumn{2}{|c|}{$3: 1$} \\
\hline & $\mathrm{N}$ & FV & $S^{x}$ & $\chi 2^{w}$ & $P$ & $\chi 2^{w}$ & $P$ \\
\hline \multicolumn{8}{|c|}{ NH2405 (NH2405 x NH614) } \\
\hline $90-1$ & 34 & 27 & 4 & 0.80 & $0.50-0.25$ & 12.07 & 0.005 \\
\hline $90-2$ & 29 & 13 & 1 & 6.10 & $0.02-0.01$ & 0.79 & $0.50-0.25$ \\
\hline $90-3$ & 46 & 13 & 5 & 18.46 & $<0.005$ & 0.28 & $0.75-0.50$ \\
\hline $90-4$ & 36 & 28 & 3 & 1.00 & $0.50-0.25$ & 12.00 & $<0.005$ \\
\hline $90-5$ & 54 & 6 & 1 & 38.40 & $<0.005$ & 7.20 & $0.01-0.005$ \\
\hline \multicolumn{8}{|c|}{$(\mathrm{NH} 2405$ x NH614) NH2405 } \\
\hline $90-1$ & 17 & 52 & 3 & 17.75 & $<0.005$ & 93.34 & $<0.005$ \\
\hline $90-2$ & 41 & 3 & 1 & 32.82 & $<0.005$ & 7.76 & $0.01-0.005$ \\
\hline $90-3$ & 27 & 27 & 1 & 0.00 & $>0.999$ & 18.00 & $<0.005$ \\
\hline $90-4$ & 56 & 7 & 10 & 38.11 & $<0.005$ & 6.48 & $0.02-0.01$ \\
\hline $90-5$ & 15 & 9 & 1 & 1.50 & $0.25-0.10$ & 2.00 & $0.25-0.10$ \\
\hline \multicolumn{8}{|c|}{ NH2405 (NH614 x NH2405) } \\
\hline $90-1$ & 31 & 13 & 0 & 7.36 & $0.01-0.005$ & 0.48 & $0.50-0.25$ \\
\hline $90-2$ & 20 & 22 & 1 & 0.10 & $0.90-0.75$ & 16.79 & $<0.005$ \\
\hline $90-3$ & 32 & 18 & 1 & 3.92 & $0.05-0.02$ & 3.23 & $0.10-0.05$ \\
\hline $90-4$ & 32 & 17 & 2 & 4.59 & $0.05-0.02$ & 2.46 & $0.25-0.10$ \\
\hline \multicolumn{8}{|c|}{ (NH614 x NH2405) NH2405 } \\
\hline $90-1$ & 28 & 20 & 0 & 1.33 & $0.25-0.10$ & 7.11 & $0.01-0.005$ \\
\hline $90-2$ & 33 & 43 & 0 & 1.32 & $0.25-0.10$ & 40.42 & $<0.005$ \\
\hline Combined & 531 & 318 & 34 & 53.44 & $<0.005$ & 70.25 & $<0.005$ \\
\hline Homogeneity & & & & 120.12 & $<0.005$ & 160.16 & $<0.005$ \\
\hline
\end{tabular}

${ }^{\overline{2}}$ Field and greenhouse plantings combined.

'Phenotypes: $\mathrm{N}=$ normal, $\mathrm{FV}=$ fused vein, $\mathrm{S}=$ sectored plant.

${ }^{x}$ Sectored data omitted from analyses.

${ }^{w} x 2$ df: individual, 1 ; combined, 1; homogeneity, 10.

ued to produce FV leaves for 4 months before succumbing to pests and low light levels. Altered terminals were also noted in 1991 among progeny of $\mathrm{N}$ backcrosses derived from the same parents.

Phenotypes. $\mathrm{F}_{2}, \mathrm{~F}_{3}$, and $\mathrm{BC}$ plants were classified into three categories: N, FV, and sectored. Progeny were considered $\mathrm{N}$ if they generated $\mathrm{N}$ leaves until the tenth leaf stage of growth in the greenhouse and until peak bloom in the field. Plants were designated FV if continual FV leaf production began by the tenth leaf stage. Sectored plants were observed only in field-grown populations derived from $\mathrm{NH} 2405 \times \mathrm{NH} 614$ andNH614 $\times$ NH2405. They produced both $\mathrm{N}$ and $\mathrm{FV}$ leaves in one of two general patterns. Either FV and $\mathrm{N}$ leaves alternated on a stem or different stems had 
Table 3. Fused vein segregations in $\mathrm{F}_{2}$ populations derived from crosses between NH2405 (fused vein) and NHBP10 (normal).

\begin{tabular}{|c|c|c|c|c|c|c|}
\hline \multirow[b]{2}{*}{ Cross } & \multicolumn{2}{|c|}{ Phenotype $^{2}$} & \multicolumn{2}{|c|}{$3: 1$} & \multicolumn{2}{|c|}{$15: 1$} \\
\hline & $\mathrm{N}$ & FV & $\chi 2^{y}$ & $P$ & $\chi 2^{y}$ & $P$ \\
\hline \multicolumn{7}{|c|}{$\mathrm{NH}_{2405 \times \mathrm{NHBP} 10 \mathrm{~F}_{2}}$} \\
\hline $91-1$ & 24 & 4 & 1.71 & $0.25-0.10$ & 3.09 & $0.10-0.05$ \\
\hline $91-2$ & 27 & 0 & 9.00 & $<0.005$ & 1.80 & $0.25-0.10$ \\
\hline $91-3$ & 36 & 0 & 12.00 & $<0.005$ & 2.40 & $0.25-0.10$ \\
\hline $91-\mathrm{S}$ & 44 & 1 & 12.45 & $<0.005$ & 1.25 & $0.50-0.25$ \\
\hline Combined & 131 & 5 & 32.98 & $<0.005$ & 1.54 & $<0.005$ \\
\hline Homogeneity & & & 2.18 & $0.75-0.50$ & 7.00 & $0.10-0.05$ \\
\hline
\end{tabular}

${ }^{\mathrm{Z}}$ Phenotypes: $\mathrm{N}=$ normal, $\mathrm{FV}=$ fused vein.

" $x 2 \mathrm{df}$ : individual, 1; combined, 1; homogeneity, 3.

Table 4. Fused vein segregations in testcross populations derived from crosses between NH2405 (fused vein) and NHBP10 (normal).

\begin{tabular}{|c|c|c|c|c|c|c|}
\hline \multirow[b]{2}{*}{ Cross } & \multicolumn{2}{|c|}{ Phenotype $^{z}$} & \multicolumn{2}{|c|}{$1: 1$} & \multicolumn{2}{|c|}{$3: 1$} \\
\hline & $\mathrm{N}$ & FV & $\chi 2^{y}$ & $P$ & $\chi 2^{y}$ & $P$ \\
\hline \multicolumn{7}{|c|}{$\overline{\mathrm{NH} 2405(\mathrm{NHBP} 10 \times \mathrm{NH} 2405)}$} \\
\hline $91-1$ & 24 & 10 & 5.76 & $0.02-0.01$ & 0.35 & $0.75-0.50$ \\
\hline $91-2$ & 21 & 3 & 13.50 & $<0.005$ & 2.00 & $0.25-0.10$ \\
\hline $91-3$ & 9 & 1 & 6.40 & $0.02-0.01$ & 1.20 & $0.50-0.25$ \\
\hline $91-4$ & 8 & 2 & 3.60 & $0.10-0.05$ & 0.13 & $0.75-0.50$ \\
\hline $91-5$ & 8 & 2 & 3.60 & $0.10-0.05$ & 0.13 & $0.75-0.50$ \\
\hline \multicolumn{7}{|c|}{$(\mathrm{NH} 2405 \times$ NHBP10)NH2405 } \\
\hline $91-1$ & 43 & 2 & 37.36 & $<0.005$ & 10.14 & $<0.005$ \\
\hline Combined & 113 & 20 & 65.03 & $<0.005$ & 7.04 & $0.01-0.005$ \\
\hline Homogeneity & & & 5.19 & $0.50-0.25$ & 6.91 & $0.25-0.10$ \\
\hline
\end{tabular}

${ }^{\overline{ }}$ Phenotypes: $\mathrm{N}=$ normal, $\mathrm{FV}=$ fused vein.

"x $2 \mathrm{df}$ : individual, 1; combined, 1; homogeneity, 5.

different leaf phenotypes. Sectored plants comprised 5.2\%. of the field grown plants and were omitted from segregation analyses because their phenotypes were ambiguous.

There was variation of expression among the FV progeny. The onset of FV leaf production ranged from the fourth to the tenth leaf stage. The extent of fusion varied from slight $(1-5 \mathrm{~cm})$ to pronounced $(10-20 \mathrm{~cm})$; the greatest vein fusion occurred in plants with the earliest onset of FV leaves and the deepest leaf lobes. The extent of fusion also increased with leaf number within each plant but stabilized by the twentieth leaf stage. Variation of expression was visibly greater between $\mathrm{F}_{3}$ populations than within. $\mathrm{FV}$ plants within a population showed similar degrees of fusion.

$F_{2}$ and testcross segregation. $\mathrm{FV}$ segregation in $\mathrm{F}_{2}$ and $\mathrm{FV} \mathrm{BC}$ populations derived from $\mathrm{NH} 2405$ and NH614 exhibited considerable heterogeneity (Tables 1 and 2). FV plants were recovered with both NH2405 and NH614 cytoplasm. Four $\mathrm{F}_{2}$ and seven testcross populations fit ratios expected for a single recessive gene (F,: $3 \mathrm{~N}$ to $1 \mathrm{FV}$; testcross: $1 \mathrm{~N}$ to $1 \mathrm{FV}$ ). Two $\mathrm{F}_{2}$ and six testcross populations fit a two gene double recessive model $\left(\mathrm{F}_{2}: 15 \mathrm{~N}\right.$ to 1 $\mathrm{FV}$; testcross: $3 \mathrm{~N}$ to $1 \mathrm{FV}$ ). Five $\mathrm{F}_{2}$ and three testcross had either no FV plants or insufficient plants to fit either model. Population sizes were too small to effectively test a three gene model. One testcross population, having $75 \% \mathrm{FV}$ plants, exceeded the expected recovery for a monogenic recessive trait. In contrast, segregating populations derived from $\mathrm{NH} 2405$ and NHBP10 were comparatively homogeneous (Tables 3 and 4). All four $\mathrm{F}_{2}$ and five of six testcross populations fit expected ratios for a double recessive model. One $\mathrm{F}^{2}$ and two testcross populations also fit a monohybrid ratio.

$F_{3}$ segregation. Inheritance data for $\mathrm{F}_{3}$ populations descending from crosses between NH2405 and both NH614 and NHBP10 are provided in Table 5. As expected for a recessive trait, $\mathrm{F}_{3}$ populations generated from $\mathrm{FV} \mathrm{F}_{2}$ plants contained only $\mathrm{FV}$ individuals. Of the ten $F_{1}$ populations produced from $\mathrm{N} \mathrm{F}_{2}$ plants, two segregated as a single recessive gene, and eight contained all $\mathrm{N}$ plants. The segregating $\mathrm{F}_{3} \mathrm{~s}$ were derived from $\mathrm{F}_{2}$ populations with high $\mathrm{FV}$ frequencies. The nonsegregating $\mathrm{F}_{3} \mathrm{~s}$ were derived from $\mathrm{F}_{2}$ populations containing few $(2 \%)$ or no FV plants, suggesting heterozygotes were also few or absent in these $F_{2}$ populations. An assumption of simple Mendelian inheritance predicts that two out of three $\mathrm{N} \mathrm{F}_{2}$ plants should segregate for a single recessive gene or eight out of fifteen for a double recessive gene.

The two $\mathrm{F}_{3}$ populations derived from sectored $\mathrm{F}_{2}$ progeny came from separate $\mathrm{F}_{2}$ plants. Both $\mathrm{F}_{2}$ plants had a $\mathrm{N}$ main stem, one $\mathrm{FV}$ lateral stem and one $\mathrm{N}$ lateral stem. Cucurbita pepo's alternating pattern of bloom necessitated pollination of female lateral stem flowers by main stem male flowers. The $\mathrm{F}_{3}$ obtained from a FV lateral segregated in a 3:1 ratio. In contrast, progeny from a $\mathrm{N}$ lateral of a second sectored $\mathrm{F}_{2}$ were all $\mathrm{N}$.

Complementation. All $\mathrm{F}_{1}, \mathrm{~F}_{2}$, and $\mathrm{BC}$ plants derived from crosses between $\mathrm{NH} 2405$ and $\mathrm{NH} 7210$ lines produced FV leaves beginning with the fourth to sixth leaf stage and then throughout vegetative growth. As with the $\mathrm{N}$ line crosses, $\mathrm{FV}$ plants in $\mathrm{F}_{2}$ and $\mathrm{BC}$ populations displayed a continuum of $\mathrm{FV}$ expression that varied both within and between plants. The variation, however, was subtle; the degree of fusion was no less or no greater than either parent. The observations suggested that $\mathrm{NH} 2405$ and $\mathrm{NH} 7210$ have identical FV genotypes, but that phenotypic expression was modified by different genetic backgrounds. An association with leaf size is possible; the moderately fused $\mathrm{NH} 7210$ has smaller leaves than $\mathrm{NH} 2405$. 
Table 5. Fused vein segregations in $\mathrm{F}_{3}$ populations derived from crosses of NH2405 (fused vein) with NH614 (normal) or NHBP10 (normal).

\begin{tabular}{|c|c|c|c|c|c|c|c|c|}
\hline \multirow[b]{2}{*}{ Cross } & \multicolumn{2}{|c|}{$\mathrm{F}_{2}$} & \multicolumn{2}{|c|}{ Phenotype $^{y}$} & \multicolumn{2}{|c|}{$3: 1$} & \multicolumn{2}{|c|}{$15: 1$} \\
\hline & Phenotype & FVFQ $^{7}$ & $\mathrm{~N}$ & $\mathrm{FV}$ & $\chi 2^{x}$ & $P$ & $\chi 2^{x}$ & $P$ \\
\hline \multicolumn{9}{|c|}{$\overline{\mathrm{NH} 2405 \times \mathrm{NH} 614 \mathrm{~F} 3}$} \\
\hline 91-13 & Fused & 0.20 & 0 & 44 & & & & \\
\hline $91-15$ & Fused & 0.20 & 0 & 47 & & & & \\
\hline $91-16$ & Fused & 0.20 & 0 & 54 & & & & \\
\hline $91-14$ & Normal & 0.20 & 32 & 13 & 0.40 & $0.75-0.50$ & 39.36 & $<0.005$ \\
\hline $91-33$ & Normal & 0.00 & 43 & 0 & & & & \\
\hline $91-41$ & Sectored $^{w}$ & 0.07 & 33 & 13 & 0.36 & $0.75-0.50$ & 38.04 & $<0.005$ \\
\hline 91-71 & Sectored $^{v}$ & 0.35 & 47 & 0 & & & & \\
\hline \multicolumn{9}{|c|}{ NH2405 $\times$ NHBP10 F3 } \\
\hline $91-11$ & Normal & 0.14 & 29 & 13 & 0.79 & $0.50-0.25$ & 43.74 & $<0.005$ \\
\hline $91-21$ & Normal & 0.00 & 42 & 0 & & & & \\
\hline $91-22$ & Normal & 0.00 & 42 & 0 & & & & \\
\hline $91-31$ & Normal & 0.00 & 37 & 0 & & & & \\
\hline $91-32$ & Normal & 0.00 & 42 & 0 & & & & \\
\hline $91-\mathrm{S} 1$ & Normal & 0.02 & 15 & 0 & & & & \\
\hline 91-S2 & Normal & 0.02 & 43 & 0 & & & & \\
\hline 91-S3 & Normal & 0.02 & 40 & 0 & & & & \\
\hline
\end{tabular}

${ }^{2} \mathrm{FVFQ}$ : fused vein frequency in $\mathrm{F}_{2}$ population.

${ }^{\mathrm{Y}}$ Phenotypes: $\mathrm{N}=$ normal, $\mathrm{FV}=$ fused vein.

${ }^{x} x 2$ df of $=1$.

"Fruit obtained from fused vein stem.

${ }^{v}$ Fruit obtained from normal stem.

\section{Discussion}

The results do not conform to a simple genetic model based solely on the normal segregation and transmission of one or two recessive genes. FV recovery varied extensively among both $\mathrm{F}_{2}$ and testcross populations with six populations having no FV plants at all. Although most populations fit either a single or double recessive gene model, a quarter of the populations had insufficient FV plants for either model. The association of segregating $F_{3}$ populations only with high $\mathrm{F}_{2} \mathrm{FV}$ frequency is inconsistent with a simple Mendelian model. The erratic and low recovery of the FV trait suggest that transmission of $\mathrm{FV}$ alleles is impeded during reproduction. A plausible hypothesis for FV inheritance is that the trait is a gametophytic subvital governed by a single recessive gene, designated $f v$. It assumes that $\mathrm{N}$ gametophytes have a selective advantage during the reproductive processes which can be either accentuated or minimized by environmental conditions.

Gametophytic selection is believed to be pervasive in angiosperms (Mulcahy, 1975; Zamir, 1983). Preferential allele transmission has been demonstrated for both single and multigenic traits in several species (Kedar et al., 1967; McGee and Baggett, 1992a, 1992b; Mulcahy et al., 1975; Mulcahy and Mulcahy, 1975; Ottaviano et al., 1983, 1988; Rabinowitch et al., 1978). Various environmental stresses have also been shown to cause differential allele transmission. (Mulinix and Iezzoni, 1988; Rodriguez-Garay and Barrow, 1988; Sacher et al., 1983; Zamir et al., 1981, 1982; Zamir and Gadish, 1987).

The populations of the first inheritance study generated from parents exposed to a fluctuating field environment throughout growth. Although plants were healthy and vigorous, they experienced daily changes in temperature, humidity, and water supply. Variable stress during the 3 weeks of pollination could be expected to create different levels of gametic competition in each flower. Consequently, populations with different genetic distributions would be produced, accounting for the first study's heterogeneity and often low FV recov- ery. In contrast, populations in the second study were created in a relatively stable, albeit suboptimal, greenhouse environment. Moderate but constant stress from short days and pot culture might be expected to produce populations with similar genetic distributions but with fewer then expected FV plants.

The $\mathrm{F}_{3}$ data are also explained by gametophytic selection. Preferential transmission of $\mathrm{N}$ alleles would have lowered the number of $\mathrm{F}$ heterozygotes and consequently the number of segregating $\mathrm{F}_{3}$ populations. Furthermore, the decrease of heterozygotes would have paralleled the decrease of homozygous recessive within each $F_{2}$ population. As expected, segregating $\mathrm{F}_{3} \mathrm{~s}$ were derived from $\mathrm{F}_{2}$ populations with relatively high $\mathrm{FV}$ frequencies.

In the first inheritance study, low FV recovery among reciprocal testcross populations indicates that selection operates on both male and female gametes, and may extend to the developing zygotes. Cucurbita pepo fruit often contain a number of undeveloped seed and selective fruit abortion in C. pepo has been associated with poor pollen load and seed set (Stephenson and Windsor, 1986; Windsor et al., 1987). Although seed homozygous for the FV trait appear normal and viable, selective abortion of zygotes may also contribute to the reduction of FV progeny. In general, however, the lowest FV recoveries occurred when $\mathrm{FV}$ and $\mathrm{N}$ pollen were in competition (i.e. from a heterozygous parent); the highest recoveries resulted when the FV parent was the pollen source. This implies that for the FV trait, the male gamete is relatively more prone to selection than the female gamete or developing zygote.

A double homozygous recessive model, e.g., $f f v v$, with gametophytic selection for one or both genes cannot be unequivocally ruled out. The appearance of one and two gene segregation and non fitting populations in the first inheritance study would result from NH614 being heterozygous for one of the two presumptive genes, $F f V V$, or $F F V v$. In the second study, NHBP10 would be homozygous dominant for both genes, $F F V V$, producing two gene segregation or nonfitting populations in crosses with a double recessive FV parent, ffvv. Although possible, this model is unlikely. NH614 and NHBP10 
were highly uniform $\mathrm{F}_{6}$ and $\mathrm{F}_{5}$ lines, respectively, when the $\mathrm{F}_{1} \mathrm{~s}$ were generated for the inheritance studies. Theoretically, $98.4 \%$ of NH614 genes were homozygous. Additional inheritance data from a pollen competition study (Carle and Loy, 1996b) also favor a single gene model.

The variation of FV expression in segregating populations can be presumed to have a genetic origin. This is inferred from the distinct and stable phenotypes of $\mathrm{NH} 2405$ and $\mathrm{NH} 7210$, from the greater variation seen between $\mathrm{F}_{2}$ populations than within, and from the uniformity of expression in $\mathrm{F}_{3}$ populations. The rapid stabilization of expression in the $\mathrm{F}_{3}$ suggests that relatively few genes modify expression. A genetic basis for FV variation implies that the trait is completely penetrant. The low recovery of FV individuals was not likely the result of FV genotypes failing to manifest the FV phenotype. Incomplete penetrance would be expected to produce sister populations with similar phenotypic classes and distributions in the same environment.

The appearance of FV terminals in $F_{1}$ plants was unexpected and unusual. The continued production of FV leaves by rooted cuttings of these terminals suggested that a permanent change of genotype may have occurred. Unfortunately, fruits from attempted selfs of the subsequent plants aborted and this was not verified. Nevertheless, an association of this phenomenon with the mix of phenotypes found in sectored $\mathrm{F}_{2}$ and testcross progeny can be conceived. If genotypic change generated the $F_{1}$ metamorphosis, then perhaps it also formed the $\mathrm{F}_{2}$ sectored plants, making them genetic chimeras.

This hypothesis of genotypic change is consistent with the segregation patterns observed in the two $\mathrm{F}_{3}$ populations derived from different sectored $\mathrm{F}_{2}$ plants. The $\mathrm{F}_{3}$ obtained from the fruit of a FV lateral presumably resulted from a cross between a homozygous recessive female flower and a heterozygous male flower. As observed, it would be expected to segregate for the FV trait. The $F_{3}$ obtained from the fruit of a $\mathrm{N}$ lateral resulted from either a cross between heterozygote and homozygous dominant flowers or between two homozygous dominant flowers. As observed, it would not be expected to segregate.

An underlying mechanism for these putative localized genotypic changes was not determined. However, several observations suggest further avenues of investigation. The frequent occurrence of the FV sectors is inconsistent with reoccurring mutation, gene conversion, and somatic crossovers as agents of genotypic change. A small chromosomal aberration could promote somatic segregation in heterozygotes through complete or partial chromosome loss or through mitotic nondisjunction. Consistent with the trait's gametic subvitality, chromosomal aberrations have been associated-with reduced fertility (Swanson et al., 1981). However, $\mathrm{FV} \times \mathrm{N} \mathrm{F}_{1} \mathrm{~s}$ have shown a significant increase in seed yield rather than a characteristic reduction in fertility (Carle and Loy, 1996b). Transposable elements can also cause localized changes in phenotype. Two elements maybe affecting FV expression in a manner similar to the way that $D s$ and $A c$ elements affect kernel color in Zea mays (Doring and Starlinger, 1986; Federoff, 1989; Shapiro, 1983).

The FV trait fulfills the genetic requirements for a roguing marker but it also has inherent weaknesses. As a rare single recessive, it can provide broad outcross detection and should be easily manipulated in breeding programs. Gametic subvitality, however, will hamper its rapid transfer to desired lines. Control of pollen competition and consideration of direction of cross will be required during cultivar development. Gametic subvitality may have a detrimental affect on fertility and seed yield, and must be evaluated. Finally, the variable expressivity of the FV trait will require selection of forms that are sufficiently fused to permit easy field identification; this may not be possible in all genetic backgrounds,

\section{Literature Cited}

Carle, R.B. and J.B. Loy. 1996a. Morphology and anatomy of the fused vein trait in Cucurbita pepo. J. Amer. Soc. Hort. Sci. 121:6-12.

Carle, R.B. and J.B. Loy. 1996b. Fused vein trait in Cucurbita pepo. associated with subvitality of the male gametophyte. J. Amer. Soc. Hort. Sci. 121:18-22.

Doring, H.P. and P. Starlinger. 1986. Molecular genetics of transposable elements in plants. Annu. Rev. Genet. 20:175-200.

Federoff, N.V. 1989. About maize transposable elements and developmerit. Cell 56:181-191.

Grebenscikov, I. 1954. Zur verebung der Dunnschaligkeit bei Cucurbita pepo. Zuchter 24:162-166.

Kedar, N., N. Reting, and J. Katan. 1967. Non random segregation of gene I for Fusarium resistance in the tomato. Euphytica 16:258-266.

McGee, J. and J.R. Baggett. 1992a. Inheritance of stringless pod in Pi sum sativum L. J. Amer. Soc. Hort. Sci. 117:628-632.

McGee, J. and J.R. Baggett. 1992b. Differential growth rate of pollen tubes from norrhal and stringless pea cultivars. HortScience 27:833-834.

Mulcahy, D.L. 1975. The biological significance of gamete competition, p. 1-3. In: D.L. Mulcahy (Ed.). Gamete competition in plants and animals. North Holland Publ. Co., Amsterdam.

Mulcahy, D.L. and G.B. Mulcahy. 1975. The influence of gametophytic competition on sporophytic quality in Dianthus dinensis. Theoret. Appl. Genet. 46:277-280.

Mulcahy, D. L., G.B. Mulcahy, and E. Ottaviano. 1975. Sporophytic expression of gametophytic competition in Petunia hybrids, p. 227232. In: D.L. Mulcahy (Ed.). Gamete competition in plants and animals. North Holland Publ. Co., Amsterdam.

Mulinix, C.A. and A.F. Iezzoni. 1988. Microgametophytic selection in two alfalfa (Medicago sativa L.) clones. Theoret. Appl. Genet. 75:9 17-922.

Ottaviano, E., D. Petroni and M.E. Pe'. 1988. Gametophytic expression of genes controlling endosperm development in maize. Theoret. Appl. Genet. 75:252-258.

Ottaviano, E., M. SarI-Gorla, and L Arenare. 1983. Male gametophytic competitive ability in maize selection and implications with regard to breeding systems, p. 367-374. In: D.L. Mulcahy and E. Ottaviano (eds.). Pollen: Biology and implications for plant breeding. Elsevier, New York. Rabinowitch, H. D., N. Retig, and N. Kedar. 1978. The mechanism of preferential fertilization in tomatoes carrying the I allele for Fusarium resistance. Euphytica 27:2 19-224.

Rodnguez-Garay, B. and J.R. Barrow. 1988. Pollen selection for heat tolerance in cotton. Crop Sci. 28:857-859.

Sacher, R. F., D.L. Mulcahy, and R.C. Staples. 1983. Developmental selection during self pollination of Lycopersicon $\times$ Solarium $\mathrm{F}_{1}$ for salt tolerance of $\mathrm{F}_{2}$, p. 329-334. In: D.L. Mulcahy and E. Ottaviano, (eds.). Pollen: Biology and implications for plant breeding. Elsevier, New York.

Shapiro, J.A. (ed.). 1983. Mobile genetic elements. Academic Press, New York. Stephenson A.G. and J.A. Windsor. 1986. Lotus corniculatus regulates offspring quality through selective fruit abortion. Evolution 40:453-458. Stuart, S.G. 1983. Comparative biochemical and genetic studies of testa development in normal and hull-less phenotypes of pumpkin (Cucurbita pepo L.). PhD. diss., Univ. of New Hampshire.

Swanson, C. P., T. Merz, and W.J. Young. 1981. Variation: Nature and consequences of altered chromosomal structure, p. 356-405. In: Cytogenetics, the chromosome in division inheritance and evolution. Prentice Hall, Englewood Cliffs, N.J.

Windsor, J.A, L.E. Davis, and A.G. Stephenson. 1987. The relationship between pollen load and fruit maturation and the effect on pollen load on offspring vigor in Cucurbita pepo. Amer. Nat. 129:643-656.

Zamir, D. 1983. Pollen gene expression and selection: applications to plant breeding, p. 3 13-330. In: S.D. Tanksley and T.J. Orton (eds.). Isozymes in plant genetics and breeding, part A. Elsevier, New York.

Zamir, D. and L Gadish. 1987. Pollen selection for low temperature adaptation in tomato. Theoret. Appl. Genet. 74:545-548.

Zamir, D., S.D. Tanksley, and R.A. Jones. 1981. Low temperature effect on selective fertilization by pollen mixtures of wild and cultivated tomato species. Theoret. Appl. Genet. 59:235-238.

Zamir, D., S.D. Tanksley, and R.A. Jones. 1982. Haploid selection for low temperature tolerance of tomato pollen. Genetics 101: 129-1 37. 